\title{
Position of Orifice of Distobuccal Canal of Maxillary Second Molars Using Cone-Beam Computed Tomography
}

This article was published in the following Dove Press journal: Clinical, Cosmetic and Investigational Dentistry

\author{
Maserat Vida' \\ Heshmatallah Shahraki \\ Ebrahimi $^{2}$ \\ Sahar Soltani ${ }^{2}$ \\ Eshagh Ali Saberi $\mathbb{1 D}^{3}$ \\ Arezoo Pirhaji ${ }^{2}$ \\ 'Department of Oral and Maxillofacial \\ Radiology, Faculty of Dentistry, Zahedan \\ University of Medical Sciences, Zahedan, \\ Iran; ${ }^{2}$ Department of Endodontics, \\ Faculty of Dentistry, Zahedan University \\ of Medical Sciences, Zahedan, Iran; \\ ${ }^{3}$ Department of Endodontics, Faculty of \\ Dentistry, Oral and Dental Diseases \\ Research Center, Zahedan University of \\ Medical Sciences, Zahedan, Iran
}

Background and Objectives: This study aimed to assess the position of distobuccal canal orifice of maxillary second molars using cone-beam computed tomography (CBCT).

Materials and Methods: A total of $301 \mathrm{CBCT}$ scans of patients were retrieved from the archives of a radiology clinic, and the distance between the orifices of distobuccal and mesiobuccal root canals, the distance between the orifices of distobuccal and palatal root canals and the angle between the orifices of mesiobuccal, distobuccal and palatal root canals in the axial plane were measured on CBCT scans.

Results: Of 301 maxillary second molars evaluated in this study, 202 (67.1\%) had three canals and 99 (32.9\%) had four canals. The distance between the distobuccal and mesiobuccal canal orifices (DM) ranged from 1.10 to $4.40 \mathrm{~mm}$ (mean: $2.1831 \pm 0.6370 \mathrm{~mm}$ ). The distance between the distobuccal and palatal canal orifices (DP) ranged from 1.20 to $6.20 \mathrm{~mm}$ (mean: $3.8704 \pm 0.84944 \mathrm{~mm}$ ). The mean angle between the mesiobuccal, distobuccal and palatal orifices (MDP) was $106.37 \pm 12.12075^{\circ}$.

Conclusion: Around one-third of maxillary second molars had four canals; the rest had three canals. No maxillary second molar with two canals was found. The orifice of distobuccal canal was located at $2 \mathrm{~mm}$ distance from the mesiobuccal canal orifice in distopalatal direction in the majority of cases. It had 3 to $4 \mathrm{~mm}$ distance from the palatal canal orifice in most cases. CBCT is recommended to find the orifice of distobuccal canal in cases in whom negotiation of this canal is challenging.

Keywords: maxillary second molars, pulp chamber, dental pulp, cone-beam computed tomography

\section{Introduction}

Missing a root canal and inefficient cleaning and shaping of all root canals are among the most common causes of failure of non-surgical endodontic treatment. Many studies have evaluated the root canal morphology in different populations. However, this topic is highly important for endodontists and general dental clinicians. ${ }^{1,2}$ The maxillary first and second molars commonly require endodontic treatment. However, they have anatomical complexities in their root canal system. ${ }^{3,4}$ Several methods have been suggested for assessment of root canal morphology. ${ }^{2}$ Three-dimensional (3D) computed tomography (CT) is a relatively new modality and chief method for assessment of root canal morphology. ${ }^{5,6}$ Conebeam computed tomography (CBCT) provides 3D scans of the maxillofacial skeleton and the teeth with a considerably lower patient radiation dose compared
Correspondence: Eshagh Ali Saberi Department of Endodontics, Faculty of Dentistry, Oral and Dental Diseases Research Center, Zahedan University of Medical Sciences, Janbazan Boulevard, Ist and 3rd Janbazan Intermediate, Unit 2, Sistan and Baluchestan, Zahedan, Iran Tel +98 9151416924

Email saberiendo@yahoo.com 
to the conventional CT. CBCT provides images of an object in axial, sagittal and coronal planes, which are used in 3D image reconstruction to determine the morphology and some other properties of an object. Moreover, CBCT is non-invasive and the samples remain intact after tomography. ${ }^{5,7}$ Evidence shows that dental clinicians can obtain valuable information about the root canal anatomy and morphology using CBCT. ${ }^{8,9}$ Lee et al ${ }^{10}$ used CBCT to assess the anatomy of the mesiobuccal canal of maxillary first and second molars in a Korean population. They detected a second mesiobuccal canal in $71.8 \%$ of first molars and $42.2 \%$ of second molars.

Alavi et $\mathrm{al}^{11}$ evaluated the root and canal morphology of maxillary molars in a Thai population. They observed that more than half of the mesiobuccal canals of first and second molars had two canals. Inter-canal communication was noted in $16 \%$ of the cases. Considering the variations in canal anatomy and morphology in different populations, this study aimed to assess the position of distobuccal canal orifice of maxillary second molars in a population residing in south-east Iran to racially determine the root canal orifice variations.

\section{Materials and Methods}

\section{Patient Selection}

This descriptive cross-sectional study was approved by the ethics committee of Zahedan University of Medical Sciences, Zahedan, Iran (IR.ZAUMS.REC. 1394.1498), and written informed consent was obtained from patients. CBCT scans were retrieved from the archives of radiology clinics in Zahedan city, Iran from 2016 to 2018. The CBCT scans had been obtained for preoperative assessment for implant treatment or for diagnostic purposes. A total of 301 three-rooted maxillary second molars of 273 patients (98 males and 175 females) with a mean age of 37.5 years (18 to 60 years) were evaluated. The inclusion criteria were as follows: The maxillary second molars had mature apices with no carious lesions and no defects. They had no coronal or root restoration, no previous endodontic treatment and no apical lesion. They did not have any calcification or root resorption. The CBCT scans had optimal quality.

\section{CBCT}

The CBCT scans had been taken using a CBCT scanner (Vatech Co., Ltd., Gyeonggi-do, Korea) with the exposure settings of $89 \mathrm{kVp}, 5.4 \mathrm{~mA}, 6 \mathrm{~s}$ exposure time, $0.2 \mathrm{~mm}$ voxel size, $90 \times 120 \mathrm{~mm}$ field of view, vertical position at the center and $1.5 \mathrm{~mm}$ slice thickness. All CBCT scans were evaluated by an experienced radiologist using Image Viewing Program (EZ3D Plus, Korea) in a dark room on a 14-inch LED flatscreen monitor (Sony) with 1280x800-pixel resolution.

\section{Image Assessment}

A total of $301 \mathrm{CBCT}$ scans of maxillary second molars were evaluated. Number of roots and canals in each tooth, the distance between the center of distobuccal and mesiobuccal canal orifices, the distance between the center of distobuccal and palatal canal orifices and the angle between the mesiobuccal, distobuccal and palatal canal orifices (MDP) were all measured. Each image was evaluated in axial section at the level of canal orifice. All measurements and analyses were carried out by one endodontist and one radiologist twice with a two-week interval. In case of disagreement, another experienced endodontist evaluated the images to reach a consensus. The data were then obtained after the final calibration.

\section{Results}

The maxillary second molars had three canals in $67.1 \%$ and four canals in $32.9 \%$ of the cases. No case had two or more than four canals (Table 1).

In 301 maxillary second molars with three and four canals, the distance between the distobuccal and mesiobuccal canal orifices (DM) ranged from 1.10 to $4.40 \mathrm{~mm}$ with a mean of $2.1831 \pm 0.63709 \mathrm{~mm}$. The distance between the orifice of distobuccal and palatal canals (DP) ranged from 1.20 to $6.20 \mathrm{~mm}$ with a mean of $3.8704 \pm 0.84944 \mathrm{~mm}$. The mean angle between the mesiobuccal, distobuccal and palatal orifices (MDP) was $106.37 \pm 12.12075^{\circ}$ (Table 2).

Table I Number and Percentage of Root Canals of Maxillary Second Molars

\begin{tabular}{|l|l|l|l|l|l|}
\hline Root Canal Number & $\mathbf{2}$ & $\mathbf{3}$ & $\mathbf{4}$ & $\mathbf{5}$ & Total \\
\hline Frequency & 0 & 202 & 99 & 0 & 301 \\
Percentage & 0.0 & 67.1 & 32.9 & 0.0 & 100.0 \\
\hline
\end{tabular}

Table 2 Mean, Standard Deviation, Minimum and Maximum Values of DM, DP in Millimeters and MDP in Degrees in Maxillary Second Molars $(n=30 \mathrm{I})$

\begin{tabular}{|l|l|l|l|l|}
\hline Distance & $\begin{array}{l}\text { Minimum } \\
(\mathbf{m m})\end{array}$ & $\begin{array}{l}\text { Maximum } \\
(\mathbf{m m})\end{array}$ & $\begin{array}{l}\text { Mean } \\
\mathbf{( m m})\end{array}$ & $\begin{array}{l}\text { Std. Deviation } \\
(\mathbf{m m})\end{array}$ \\
\hline DM & 1.10 & 4.40 & 2.1831 & 0.63709 \\
DP & 1.20 & 6.20 & 3.8704 & 0.84944 \\
MDP & 80.40 & 144.50 & 106.37 & 12.12075 \\
\hline
\end{tabular}


Table 3 DM (Distance Between the Distobuccal and Mesiobuccal Canal Orifices) Variations in Millimeters

\begin{tabular}{|l|l|l|l|l|l|l|l|l|l|}
\hline DM & $\sim 1$ & $\sim 1.5$ & $\sim 2$ & $\sim 2.5$ & $\sim 3$ & $\sim 3.5$ & $\sim 4$ & $\sim 4.5$ & Total \\
\hline Frequency & 0 & 50 & 92 & 80 & 49 & 20 & 8 & 2 & 301 \\
Percentage & 0.0 & 16.6 & 30.6 & 26.6 & 16.3 & 6.6 & 2.7 & 0.7 & 100 \\
\hline
\end{tabular}

Table 4 DP (Distance Between the Distobuccal and Palatal Canal Orifices) Variations in Millimeters

\begin{tabular}{|l|l|l|l|l|l|l|l|l|l|l|l|l|l|}
\hline DP & $\sim 1$ & $\sim 1.5$ & $\sim 2$ & $\sim 2.5$ & $\sim 3$ & $\sim 3.5$ & $\sim 4$ & $\sim 4.5$ & $\sim 5$ & $\sim 5.5$ & $\sim 6$ & $\sim 6.5$ & Total \\
\hline Frequency & 0 & 3 & 6 & 13 & 18 & 56 & 81 & 53 & 52 & 11 & 7 & 1 & 301 \\
Percentage & 0.0 & 1 & 2 & 4.3 & 6 & 18.6 & 26.9 & 17.6 & 17.3 & 3.7 & 2.3 & 0.3 & 100 \\
\hline
\end{tabular}

DM was in the range of 1.5 to $3 \mathrm{~mm}$ in $90 \%$ of the teeth; in the remaining $10 \%$, it was in the range of 3.5 to $4.5 \mathrm{~mm}$ (Table 3). DP ranged from 3.5 to $5 \mathrm{~mm}$ in $80.4 \%$ of the cases. In $13.3 \%$ of the cases, it was in the range of 1.5 to $3 \mathrm{~mm}$ and in $6.3 \%$ of the cases, it was in the range of 5.5 to $6.5 \mathrm{~mm}$ (Table 4).

MDP was in the range of $80.4^{\circ}$ to $144.5^{\circ}$ such that this value ranged from 90 to $120^{\circ}$ in $80 \%$ of the teeth. In $7.3 \%$, this value was smaller than $90^{\circ}$ and in $13.3 \%$, it was larger than $120^{\circ}$ (Tables 5 and 6 and Figure 1).

\section{Discussion}

Success of root canal treatment depends on possession of a complete knowledge about tooth anatomy and morphology of the root canal system, which may be variable within the normal range. ${ }^{12}$ Although the external morphology and internal anatomy of the teeth appear to be the same, a high variability exists in this respect. Permanent teeth have wide variations in the number of roots, number and shape of canals in each root and root fusion. ${ }^{13}$ Several

Table 5 Frequency Distribution of MDP Angle Variations $\left(<90^{\circ}\right.$, $90-120^{\circ}$ and $>120^{\circ}$ )

\begin{tabular}{|l|l|l|}
\hline MDP & Frequency & Percentage \\
\hline$<90^{\circ}$ & 22 & 7.3 \\
$90-120^{\circ}$ & 239 & 79.4 \\
$>120^{\circ}$ & 40 & 13.3 \\
Total & 301 & 100.0 \\
\hline
\end{tabular}

factors are responsible for the variability in results such as age, gender and race. Also, difference in the reported results may be due to study design and methodology. ${ }^{14,15}$

$\mathrm{CBCT}$ is a commonly used radiographic modality for assessment of the anatomy and morphology of the root canal system. ${ }^{16}$ It does not have the limitations of $2 \mathrm{D}$ radiography and has lower patient radiation dose and higher resolution than medical CT. CBCT is extensively used in implantology, orthodontics, oral and maxillofacial reconstruction, diagnosis prior to root canal treatment and assessment of the quality of root canal preparation, obturation and retreatment. ${ }^{17}$

Blattner et al, in 2010 showed that the second mesiobuccal canal could be detected in $78.95 \%$ of the cases and there was no significant difference in the ability of CBCT for detection of second mesiobuccal canal compared to clinical sectioning (gold standard). ${ }^{18}$ Angelopoulos et al, in 2008 indicated that CBCT provides reliable results since it does not cause magnification or distortion. ${ }^{19}$

Since studies on the position of distobuccal canal orifice of maxillary second molars are limited, this study used $\mathrm{CBCT}$ as a non-invasive modality to assess the position of distobuccal canal orifice of maxillary second molars. The current results showed that $67.1 \%$ of maxillary second molars had three canals and $32.9 \%$ had four canals.

Rouhani et al, in 2014 demonstrated that only 1.6\% of maxillary second molars of an Iranian subpopulation had four roots and $98.4 \%$ had three roots. ${ }^{20}$ Zhang et al, in 2011 showed that maxillary second molars had one root in $10 \%$, two roots in

Table 6 MDP (the Angle Formed by the Mesiobuccal, Distobuccal and Palatal Canal Orifices) Variability

\begin{tabular}{|l|l|l|l|l|l|l|l|l|}
\hline MDP & $\mathbf{8 0 - 9 0 ^ { \circ }}$ & $\sim 100^{\circ}$ & $\sim 1 \mathbf{1}^{\circ}$ & $\sim 120^{\circ}$ & $\sim 130^{\circ}$ & $\sim 140^{\circ}$ & $\sim 150^{\circ}$ & Total $^{\circ}$ \\
\hline $\begin{array}{l}\text { Frequency } \\
\text { Percentage }\end{array}$ & 22 & 71 & 99 & 69 & 31 & 7 & 2 & 301 \\
& 7.3 & 23.6 & 32.9 & 22.9 & 10.3 & 2.3 & 0.7 & 100 \\
\hline
\end{tabular}



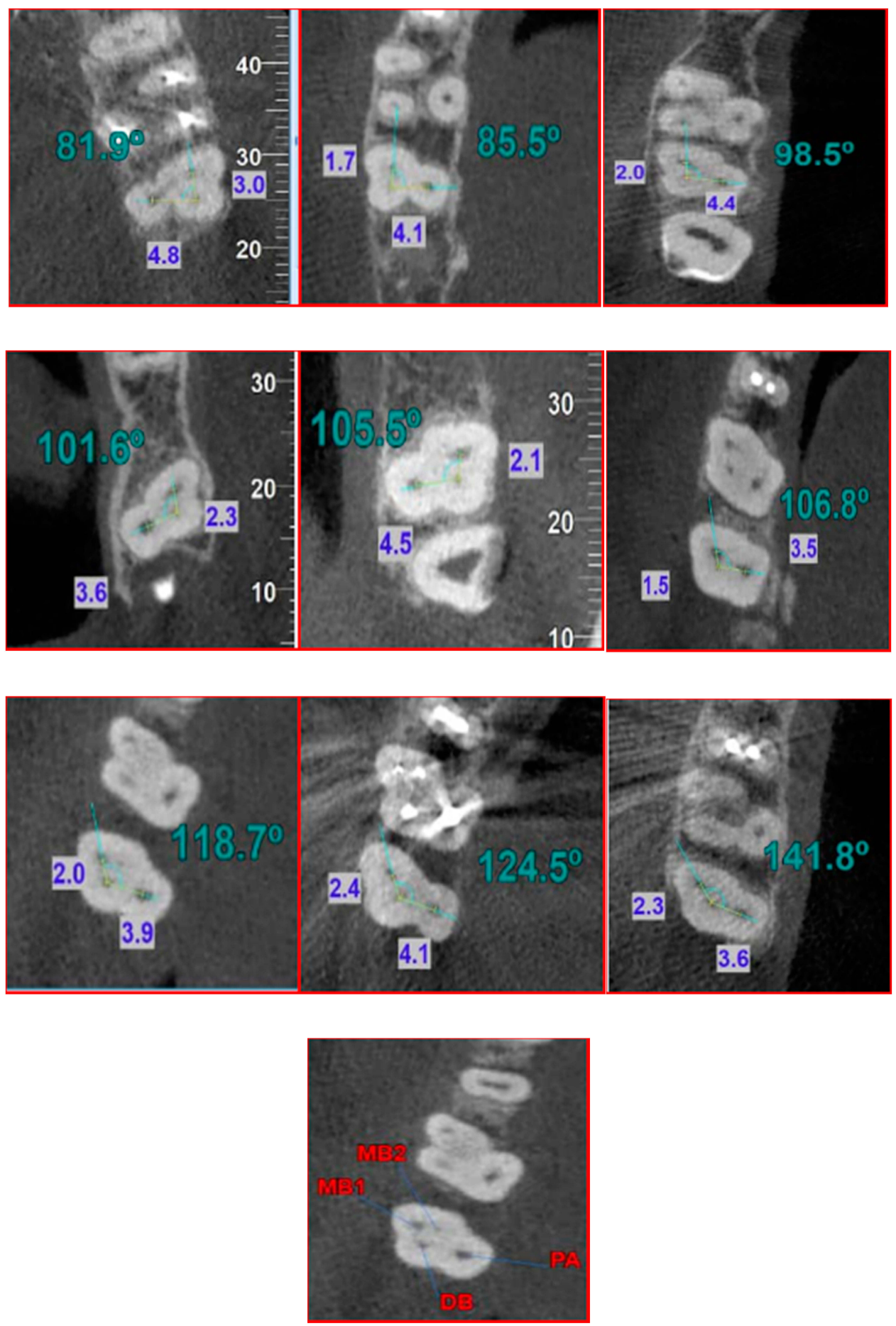

Figure I Images of transverse section of the orifice in different cases. From left to right and from top to bottom: $M D P<90^{\circ}$ and $M D P>\mid 40^{\circ}$. Blue values show distance between the orifices of distobuccal and mesiobuccal canals (DM), and distance between the orifices of distobuccal and palatal canals (DP). Green values show the angle between the orifices of mesiobuccal, distobuccal and palatal canals (MDP). Red values indicate the canal orifices of four-canal maxillary second molars.

$8 \%$ and three roots in $81 \%$ of the cases. ${ }^{21} \mathrm{Kim}$ et al, in 2012 demonstrated that maxillary second molars in a Korean population had three or four roots in $82.2 \%$ of the cases; an additional canal was present in distobuccal root in $0.30 \%$ of the cases. $^{22}$
In this study, the mean distance between the orifices of distobuccal and mesiobuccal root canals was $2.18 \pm 0.63 \mathrm{~mm}$ (range 1.1 to $4.4 \mathrm{~mm}$ ). This distance was in the range of 1.5 to $3 \mathrm{~mm}$ in $90 \%$ of the cases, which was in agreement with the results of Han et al, in 2012. They reported that this distance 
was 0.7 to $4.8 \mathrm{~mm}$ in a Chinese population and 1.5 to $3 \mathrm{~mm}$ in $81.39 \%$ of the cases. ${ }^{23}$ The current findings revealed that the mean distance between the distobuccal and palatal root canal orifices was $3.87 \pm 0.84 \mathrm{~mm}$; this value ranged from 1.7 to $6 \mathrm{~mm}$. In $80.4 \%$ of the samples, this distance ranged from 3.5 to $5 \mathrm{~mm}$ while it was $<3 \mathrm{~mm}$ in $13.3 \%$ and $>5 \mathrm{~mm}$ in $6.3 \%$. In our study, this distance was in the range of 3 to $5 \mathrm{~mm}$ in $90 \%$ of the cases; this finding was in agreement with the results of Han et al. They demonstrated that the DP distance was 0.8 to $6.7 \mathrm{~mm}$ in a Chinese population; this distance was 3 to $5 \mathrm{~mm}$ in $76.67 \%$ of the cases in their study. ${ }^{23}$

Assessment of the angle formed between the mesiobuccal, distobuccal and palatal (MDP) canal orifices revealed that the mean value of this angle was $106.37^{\circ} \pm 12.12^{\circ}$ (range $80.4^{\circ}$ to $144.50^{\circ}$ ); this value ranged from $90^{\circ}$ to $120^{\circ}$ in $80 \%$ of the cases, which indicates that the distobuccal canal orifice had less of a distal (23.6\%) and more of a distopalatal $(55.8 \%)$ position compared with the first mesiobuccal canal orifice, which was in agreement with the results of previous studies. ${ }^{10,23}$ Two theories can be suggested for cases in whom this angle was $>120^{\circ}$. The first theory relates to the displacement of distobuccal root towards the mesial. The second theory is displacement of the palatal root towards the distal. Both of these occurrences can increase the angle between the orifices. However, further studies are required to further elucidate this topic. Moreover, our study showed that this angle was $>120^{\circ}$ in $13 \%$ of the cases, which indicates that the position of orifice was closer to the line connecting the mesiobuccal and palatal canals. There is a possibility that the load applied from the distal surface causes mesiopalatal movement of distobuccal root during tooth development and eruption due to the thinness of buccal bone, which may complicate canal negotiation during endodontic treatment. ${ }^{23}$ Alternatively, a load applied from the mesial can cause displacement of palatal root towards the distal. Care must be taken to first negotiate the area distal to the developmental groove connecting the mesiobuccal and palatal canal orifices, which is easily accessible to find the distobuccal canal without additional extension of the access cavity towards the distal. If the canal was not found, the access cavity can be extended distopalatally to find the distobuccal canal orifice. Also, our results showed that this angle was $<90^{\circ}$ in $7.3 \%$ of the cases, which indicates the more buccal position of distobuccal canal orifice or more mesial position of palatal canal orifice, which make it challenging to find the distobuccal canal orifice. Thus, if the canal orifice is not found in distopalatal position or around the line connecting the mesiobuccal and palatal canal orifices, CBCT can be used to evaluate the presence/absence of canal without further extension of the access cavity to avoid missing of a canal. Han et al demonstrated that the MDP angle ranged from 69.4 to $174.7^{\circ}$; this range was 90 to $140^{\circ}$ in $92.8 \%$ of the cases; it was $<90^{\circ}$ in $1.83 \%$ of the cases. ${ }^{23}$ Their results were different from ours, which may be attributed to racial differences and different sample size.

\section{Conclusion}

The results showed that the position of distobuccal canal orifice was variable in maxillary second molars, which makes it difficult to negotiate this canal. Thus, CBCT can be used to reveal the position of canal orifices especially the distobuccal canal orifice during endodontic treatment.

\section{Acknowledgment}

The authors would like to thank the Research and Technology Deputy of Zahedan University of Medical Sciences for financially supporting this manuscript. Also, the authors appreciate the cooperation of Marzneshinan radiology clinic for provision of $\mathrm{CBCT}$ images.

\section{Disclosure}

The authors deny any conflicts of interest related to this study.

\section{References}

1. Ng YL, Aung T, Alavi A, Gulabivala K. Root and canal morphology of Burmese maxillary molars. Int Endod J. 2001;34(8):620-630. doi:10.1046/j.1365-2591.2001.00438.x

2. Neelakantan P, Subbarao C, Ahuja R, Subbarao CV, Gutmann JL. Cone-beam computed tomography study of root and canal morphology of maxillary first and second molars in an Indian population. $J$ Endod. 2010;36(10):1622-1627. doi:10.1016/j.joen.2010.07.006

3. Neelakantan P, Subbarao C, Subbarao CV. Comparative evaluation of modified canal staining and clearing technique, cone-beam computed tomography, peripheral quantitative computed tomography, spiral computed tomography, and plain and contrast medium-enhanced digital radiography in studying root canal morphology. J Endod. 2010;36 (9):1547-1551. doi:10.1016/j.joen.2010.05.008

4. Lewis AB, Garn SM. The relationship between tooth formation and other maturational factors. Angle Orthod. 1960;30(2):70-77.

5. Mao T, Neelakantan P. Three-dimensional imaging modalities in endodontics. Imaging Sci Dent. 2014;44(3):177-183. doi:10.5624/ isd.2014.44.3.177

6. Ghasemi N, Rahimi S, Shahi S, Samiei M, Reyhani MF, Ranjkesh B. A review on root anatomy and canal configuration of the maxillary second molars. Iran Endod J. 2017;12(1):1.

7. Abuabara A, Baratto-Filho F, Aguiar Anele J, Leonardi DP, SousaNeto MD. Efficacy of clinical and radiological methods to identify second mesiobuccal canals in maxillary first molars. Acta Odontol Scand. 2013;71(1):205-209. doi:10.3109/00016357.2011. 654262 
8. Zeng C, Shen Y, Guan X, Wang X, Fan M, Li Y. Rare root canal configuration of bilateral maxillary second molar using cone-beam computed tomographic scanning. J Endod. 2016;42(4):673-677. doi:10.1016/j.joen.2015.12.028

9. Sobhani MA, Razmi H, Sadegh M. Evaluation of anatomy and morphology of human mandibular premolar teeth by cone-beam computed tomography in Iranian population. J Dent Med. 2013;26(3).

10. Lee J-H, Kim K-D, Lee J-K, et al. Mesiobuccal root canal anatomy of Korean maxillary first and second molars by cone-beam computed tomography. Oral Surg Oral Med Oral Pathol Oral Radiol Endod. 2011;111(6):785-791. doi:10.1016/j.tripleo.2010.11.026

11. Alavi A, Opasanon A, Ng YL, Gulabivala K. Abstract. Int Endod J. 2002;35(5):478-485. doi:10.1046/j.1365-2591.2002.00511.x

12. Khedmat S, Assadian H, Saravani AA. Root canal morphology of the mandibular first premolars in an Iranian population using cross-sections and radiography. J Endod. 2010;36(2):214-217. doi:10.1016/j.joen.20 09.10 .002

13. Holderrieth S, Gernhardt CR. Maxillary molars with morphologic variations of the palatal root canals: a report of four cases. J Endod. 2009;35(7):1060-1065. doi:10.1016/j.joen.2009.04.029

14. Naseri M, Mozayeni MA, Safi Y, Heidarnia M, Baghban AA, Norouzi N. Root canal morphology of maxillary second molars according to age and gender in a selected Iranian population: a cone-beam computed tomography evaluation. Iran Endod J. 2018;13(3):373.

15. Brown P, Herbranson E. Dental Anatomy \& 3D Tooth Atlas Version 3.0. Carol Stream, IL: Quintessence; 2005.

16. Parirokh M, Razifar M, Manochehrifar H, et al. Treatment of a maxillary second molar with one buccal and two palatal roots confirmed with cone-beam computed tomography. Iran Endod J. 2017;12(3):371.
17. Matherne RP, Angelopoulos C, Kulild JC, Tira D. Use of cone-beam computed tomography to identify root canal systems in vitro. J Endod. 2008;34(1):87-89. doi:10.1016/j.joen.2007.10.016

18. Blattner TC, George N, Lee CC, Kumar V, Yelton CD. Efficacy of cone-beam computed tomography as a modality to accurately identify the presence of second mesiobuccal canals in maxillary first and second molars: a pilot study. J Endod. 2010;36(5):867-870. doi:10.1016/j.joen.2009.12.023

19. Angelopoulos C, Thomas S, Hechler S, Parissis N, Hlavacek M. Comparison between digital panoramic radiography and cone-beam computed tomography for the identification of the mandibular canal as part of presurgical dental implant assessment. J Oral Maxillofac Surg. 2008;66(10):2130-2135. doi:10.1016/j.joms.2008.06.021

20. Rouhani A, Bagherpour A, Akbari M, Azizi M, Nejat A, Naghavi N. Cone-beam computed tomography evaluation of maxillary first and second molars in Iranian population: a morphological study. Iran Endod J. 2014;9(3):190.

21. Zhang R, Wang H, Tian YY, Yu X, Hu T, Dummer PMH. Use of cone-beam computed tomography to evaluate root and canal morphology of mandibular molars in Chinese individuals. Int Endod J. 2011;44(11):990-999. doi:10.1111/j.1365-2591.2011.01904.x

22. Kim Y, Lee S-J WJ. Morphology of maxillary first and second molars analyzed by cone-beam computed tomography in a Korean population: variations in the number of roots and canals and the incidence of fusion. J Endod. 2012;38(8):1063-1068. doi:10.1016/j.joen.2012.04.025

23. Han X, Yang H, Li G, Yang L, Tian C, Wang Y. A study of the distobuccal root canal orifice of the maxillary second molars in Chinese individuals evaluated by cone-beam computed tomography. J Appl Oral Sci. 2012;20 (5):563-567. doi:10.1590/S1678-77572012000500012

\section{Publish your work in this journal}

Clinical, Cosmetic and Investigational Dentistry is an international, peer-reviewed, open access, online journal focusing on the latest clinical and experimental research in dentistry with specific emphasis on cosmetic interventions. Innovative developments in dental materials, techniques and devices that improve outcomes and patient satisfaction and preference will be highlighted. The manuscript management system is completely online and includes a very quick and fair peer-review system, which is all easy to use. Visit http://www.dovepress.com/testimonials.php to read real quotes from published authors. 